unless certain conditions prevail. The organism must be introduced into the uterus, dead tissue must be present at the time, and the injured tissue must remain in the uterus for long enough to permit incubation. In our patient probably the organism was introduced into the uterus from bowel during the unsuccessful attempt at amniocentesis, because the high vaginal swab taken before the abortion was negative for clostridia.

$\mathrm{Cl}$ welchii septicaemia, especially when haemolysis is present, is regarded as an indication for total abdominal hysterectomy. The improved survival rates of the early 1970s were attributed to this aggressive surgical approach. ${ }^{2}$ In the absence of haemolysis, however, prompt and adequate antibiotic treatment with immediate curettage will often effect a cure if coupled with good supportive care. ${ }^{3}$

We are grateful to Mr M E Pawson and Dr J Curtis for permission to publish this case report.

${ }^{1}$ Douglas GW. Toxic effects of Welch bacillus in post abortal infection. NY State $\mathcal{F}$ Med 1956;56:3673-7.

2 Decker WH, Hall W. Treatment of abortion infected with Clostridium welchii. Am F Obstet Gynecol 1966;95:394-9.

${ }^{3}$ Pritchard JA, Whalley PJ. Abortion complicated by Clostridium perfringens infection. Am $\mathcal{F}$ Obstet Gynecol 1971;111:484-92.

4 Medical Research Council Working Party on Amniocentesis. Assessment of the hazards of amniocentesis. Br $\mathcal{F}$ Obstet Gynaecol 1978;85:suppl 2.

5 United States National Institute of Child Health and Human Development Study Group. Mid-trimester amniocentesis for prenatal diagnosis. Safety and accuracy. $\mathcal{F} A M A 1976 ; 236: 1471-6$.

(Accepted 12 December 1983)

West London and Charing Cross Hospital, London W6 $7 D Q$

R E FRAY, MRCOG, senior registrar, department of obstetrics and gynaecology

T P DAVIS, FFARCs, senior registrar, department of anaesthesia

E A BROWN, MRCP, senior registrar, department of medicine

Correspondence to: Mr R E Fray.

\section{Diagnosis of encephalitozoonosis in man by serological tests}

Encephalitozoon cuniculi causes lesions in the central nervous system and the kidneys in small mammals. ${ }^{1}$ Few cases have been reported in man, and most have been in patients with immunosuppression. Serological testing for encephalitozoonosis has not previously been attempted in man but is used in veterinary practice. We used indirect immunofluorescence to examine 22 serum samples from patients with disorders of the central nervous system of uncertain origin. One sample gave clearly positive results for $E$ cuniculi, and we report on the patient.

\section{Case report}

A boy born in Colombia, probably early in 1980, was taken to an orphanage and in 1981 adopted by a Swedish family. Earlier health records were not available, but he was healthy on arrival in Sweden and growth and development progressed normally.

In May 1982 he was admitted to hospital when generalised convulsive seizures with left sided predominance developed after light facial trauma. His temperature was normal. Examination showed slight liver enlargement. Serum alanine and aspartate transaminase activities were 1.45 and $1.74 \mathrm{mmol} / \mathrm{l}$ (87 and $104 \mathrm{IU} / 1)$. Further laboratory tests did not indicate any acquired or congenital infection. Lumbar puncture, a skull $x$ ray film, and repeated electroencephalograms did not show any abnormality. Five weeks later a further left sided seizure occurred. On one occasion a right sided brain focus was recorded on electroencephalography, but this could not later be verified. Computed tomography of the brain gave normal results. Serological tests performed in July showed antibodies to $E$ cuniculi, and as animals infected with this organism excrete spores in the urine ${ }^{1}$ urological analysis was performed. Intravenous pyelography yielded normal results, and blood urea concentration and urine osmolality were normal; there was no proteinuria or glucosuria. Gram positive organisms, however, with nuclei that stained blue with Giemsa, were seen twice in sediments. The organisms, lying free or in aggregates, measured $1.5 \times 2.5 \mu \mathrm{m}$ and reacted with a fluorescent anti- $E$ cuniculi conjugate. Intraperitoneal injection of urine samples into mice free of encephalitozoonosis resulted, after three weeks, in growth of organisms indistinguishable from $E$ cuniculi in two of five animals. Ascitic fluid from the mice induced growth of the parasite after three weeks when added to dog kidney cell cultures. Later attempts to culture the organism from urine samples were unsuccessful. He was given carbamazepine $90 \mathrm{mg}$ twice daily as a prophylactic anticonvulsive and discharged from hospital.

In late August he was readmitted because of respiratory tract infection, raised temperature, and a swollen left knee. Aspirated joint fluid was aseptic, containing mononuclear cells but no antibodies to $E$ cuniculi. In September stiffness of the shoulders and vertebral joints supervened, and the right knee became swollen. Indomethacin $20 \mathrm{mg}$ daily and chloroquine $125 \mathrm{mg}$ daily were started but he did not begin to recover until intra-articular knee injections of dexamethasone $40 \mathrm{mg}$ were given in December. His health remained excellent after his discharge from hospital in February 1983. Indomethacin was stopped in December and chloroquine in May, but he continued to take carbamazepine $90 \mathrm{mg}$ twice daily.

All serum samples showed high IgG titres against $E$ cuniculi $(\because 1 / 2560)$. One sample taken in 1981 also showed $\operatorname{IgM}$ antibodies (1/160). Serum alanine and aspartate transaminase activities increased during October 1982 to 5.62 and $3.32 \mathrm{mmol} / \mathrm{l}(337$ and $199 \mathrm{IU} / \mathrm{l})$ but returned to normal $(0.59$ and $0.41 \mathrm{mmol} / \mathrm{l}(35$ and $25 \mathrm{IU} / \mathrm{l})$ ) in December. His erythrocyte sedimentation rate increased to $59 \mathrm{~mm}$ in the first hour before becoming normal in February 1983. Lymphocyte examinations performed in October 1982 and June 1983 showed normal B cell counts and low (1.0) ratios of helper to suppressor $T$ cells, but suppressor $\mathrm{T}$ cells were never increased.

\section{Comment}

This patient was clearly infected by a microsporidian, presumably E cuniculi, and IgM antibodies suggest that he was infected before his arrival in Sweden. The seizures probably reflected infection in the brain, and the arthritic symptoms may have been sequelae of infection, but neither can be attributed with certainty to the parasite. There was, however, a striking similarity to another case of encephalitozoonosis, in which spores of $E$ cuniculi were found in the cerebrospinal fluid and urine of a boy who had seizures and later recovered. ${ }^{3}$ Little is known about the pathology of encephalitozoonosis in man, but an intact immune system seems to arrest the infection as most cases have occurred in immunocompromised patients. ${ }^{2}$ Furthermore, animal studies show that functioning $T$ cells are necessary to prevent infection with $E$ cuniculi. ${ }^{4}$ Depression of immunity dependent on $T$ cells has been observed in several parasitoses, and an increased prevalence of antibody to $E$ cuniculi has been detected in patients with parasitoses, particularly malaria. ${ }^{5}$ Although our patient had no sign of any other parasitic disease, there was a lymphocyte abnormality, but its relation to $E$ cuniculi remains obscure.

We believe that this is the first reported case in which specific antibodies as well as the parasite have been found in man. Currently available data suggest that encephalitozoonosis is more common than has been thought. The difficulty of finding the parasite, because it lives in internal organ: and only briefly appears in body fluids, may explain the few cases reported in man.

${ }^{1}$ Shadduck JA, Pakes SP. Encephalitozoonosis (nosematosis) and toxoplasmosis. Am ₹ Pathol 1971;64:657-71.

2 Bywater JEC. Is encephalitozoonosis a zoonosis? Laboratory Animals $1979 ; 13: 149-51$.

${ }^{3}$ Matsubayashi H, Koike T, Mikata T, Hagiwara S. A case of Encephalitozoon-like body infection in man. AMA Arch Pathol 1959;67:181-7.

' Niederkorn JY, Shadduck JA, Schmidt ES. Susceptibility of selected inbred strains of mice to Encephalitozoon cuniculi. $\mathcal{F}$ Infect Dis 1981; 144:249-53.

singh M, Kane GJ, Mackinlay L, et al. Detection of antibodies to Nosema cuniculi (protozoa: microsporidia) in human and animal sera by the indirect fluorescent antibody technique. Southeast Asian $\mathcal{F}$ Trop Med Public Health 1982;13:110-3.

(Accepted 22 December 1983)

Department of Parasitology, National Bacteriological Laboratory, Stockholm, Sweden

N R BERGQUIST, MD, PHD, senior physician

Department of Paediatrics, St Göran's Hospital, Stockholm, Sweden

G STINTZING, MD, PHD, senior physician

L SMEDMAN, MD, physician

Department of Parasitology, National Veterinary Institute, Uppsala, Sweden

T WALLER, DVM, PHD, veterinary parasitologist

Department of Infectious Diseases, Roslagstull's Hospital, Stockholm, Sweden

T ANDERSSON, MD, senior physician

Correspondence to: Dr N R Bergquist. 